\title{
Pattern of Semen Analysis at Andrology Lab of Bangabandhu Sheikh Mujib Medical University: Findings and the Shortcomings to Overcome.
}

\author{
Shakeela Ishrat ${ }^{1}$, Parveen Fatima ${ }^{2}$, Nurjahan Begum ${ }^{3}$, Afruna Rahman Diti ${ }^{4}$ \\ ${ }^{1}$ Assistant Professor, Infertility wing, Department of Obstetrics \& Gynaecology, ${ }^{2}$ Professor, Infertility wing, Department of Obstetrics \& Gynaecology, \\ ${ }^{3}$ Assistant Professor, Infertility wing, Department of Obstetrics \& Gynaecology, BSMMU ${ }^{4}$ Project Research Officer, Centre for Child and Adolescent \\ Health, ICDDR,B, Dhaka
}

\begin{abstract}
:
Background: The Infertility wing dept. of gyne \& obst. at BSMMU provides services to the infertile couples who are referred from primary care levels and who cannot afford the expensive private facilities. The semen analysis is performed for the male partners of infertile couples at the Andrology Lab of BSMMU for detecting male factor abnormalities. Objectives: The objectives of the study is to find out the pattern of semen parameters in our population and to find out the frequency and type of abnormal semen parameters. Methods: This is a retrospective descriptive study of the semen analysis performed at the Andrology Lab of BSMMU during the year 2011. A total of 200 consecutive samples were analysed. The procedure and reference values were according to the WHO guidelines 1999. Results: Semen parameters were abnormal in $38.5 \%$ of semen analysis. Severe male factor abnormality (azospermia and severe oligospermia combined) was in $28 \%$. Sperm concentration had the highest variability followed by motility and morphology respectively in the normoozospermic males. Conclusion: Severe oligospermia and azospermia are the most common abnormalities among the infertile men presenting at the Infertility unit of BSMMU. It is recommended that the service at the Infertility wing of BSMMU should be more focused on these male factor abnormalities.
\end{abstract}

Key words: semen analysis

[BSMMU J 2014 ; 7 (2) : 103-107]

\section{Introduction:}

Male factor is a major cause of infertility in couples who fail to conceive. Male factor is solely responsible in $20 \%$ of subfertile couples and contributory in another $17 \% \%^{1}$. Semen analysis is the basic and minimum investigation to do for diagnosing male factor. In fact it is the first step towards diagnosis of male factor in fertility work up.

During ejaculation, semen is produced from a concentrated suspension of spermatozoa stored in paired epididymis mixed with fluid secretion from the accessory sex glands. The total number of spermatozoa reflect sperm production by the testis and the patency of post testicular duct system. The total fluid volume reflects the

Address for Correspondence: Dr. Shakeela Ishrat Assistant Professor, Infertility wing, Department of Obstetrics \& Gynaecology, BSMMU Cell phone: 017129897221, E-mail: shakeelaishrat@ yahoo.com secretory activity of glands. The nature of spermatozoa (concentration, vitality, motility and morphology) and the composition of seminal fluid are important for sperm function.

Semen analysis is the study of semen parameters namely volume, $\mathrm{pH}$, sperm count, sperm motility and sperm morphology. Semen analysis is performed in almost all standard pathological laboratories of Bangladesh . Bangabandhu Sheikh Mujib Medical University (BSMMU) is only public sector center in the country receiving referral of infertility patients. The Infertility unit of BSMMU has been providing comprehensive diagnostic and therapeutic service (excluding assisted reproductive techniques) to the infertile couples since 2003. The Andrology Lab at the Infertility unit of the Department of Obstetrics and 
Gynaecology of BSMMU performs the semen analysis of the male partners of infertile couples presenting for infertility workup. The methods and the reference values at the Andrology Lab follows the WHO manual for examination of semen and sperm-cervical mucus interaction ${ }^{2}$ (WHO guidelines 1999). The study was based on the reports of semen analysis performed at the Andrology Lab during the year 2011. The objective of the study was to define the pattern of normal semen parameters in our infertile patient population and to find out the frequency of abnormal semen parameters.

\section{Methods :}

The study was a descriptive analysis of the retrospective data collected and compiled at Andrology Lab of BSMMU. In the year 2011, a total of 2288 infertile couples attended the Infertility unit outdoor at BSMMU for the first time. With a prevalence of infertility at $15 \%$, the sample size was estimated to be 192. A total of 200 sequential semen analysis was taken for the study.

Semen analysis in the Andrology Lab of BSMMU follows the WHO guidelines 1999. The men provided semen for analysis after a minimum of 3 days and a maximum of 5 days abstinence. The sample was collected in a private room near Andrology Lab. The specimen container was kept in room temperature for liquefaction. Liquefaction and appearance of the semen was assessed between 30 and 60 minutes. Semen volume was measured by aspirating the semen into a graduated syringe. The $\mathrm{pH}$ of the semen was measured by $\mathrm{pH}$ paper. Microscopic examination of unstained preparation of fresh semen was done for sperm number, motility and morphology using a light microscope in a Makler counting chamber.

The reference values and terminology used are enumerated as follows.
Normal seminal fluid analysis ( World Health

Organisation,2002) 2

- Volume $>2 \mathrm{ml}$

- Sperm concentration $>20 \mathrm{million} / \mathrm{ml}$

- Sperm motility $>50 \%$ progressive or $>25 \%$ rapidly progressive

- Morphology ( strict criteria) $>15 \%$ normal forms

- White blood cells $<1$ million $/ \mathrm{ml}$

- Immunobead or mixed antiglobin reaction test* $<10 \%$ coated

*tests for the presence of antibodies coating the sperm

Semen analysis terminology 2

- Normozoospermia-all semen parameters normal

- Oligozoospermia-reduced sperm numbers

Mild to moderate : $5-20$ million/ $\mathrm{ml}$ of semen Severe : $<5$ million/ml of semen

- Asthenoozospermia-reduced sperm motility

- Teratoozospermia-Increased abnormal forms of sperm

- Oligoasthenoteratoozospermia—sperm variabls all subnormal

- Azospermia-no sperm is semen

- Aspermia( anejaculation)-no ejaculate (ejaculation failure)

- Leucocytospermia-increased white cells in semen

- Necroozospermia - all sperm are non viable or nonmotile.

Descriptive statistical analysis was done using SPSS software version 18 .

\section{Results :}

A total of 200 reports of semen analysis ( calculated and estimated sample size 192) were taken for the study. The age of the subjects ranged from 22-60 years. A total of 49 subjects $(24.1 \%$ ) had semen volume less thal $2 \mathrm{ml}$. In 
patients with normospermia semen volume was less than $2 \mathrm{ml}$.

All azospermic patients and those having $<10$ sperm per high power field had $\mathrm{pH} 8$. All the other semen specimen had $\mathrm{pH}$ value 7.5 .

Table I shows the normospermia as well as other abnormalities causing infertility of the male. Abnormalities were present in $38.5 \%$ of the semen analysis. The most common abnormality was azoospermia (17.5\%). The Andrology Lab reports lower reference limit of normal morphology as $14 \% 3$ and accordingly teratospermia was 6\%. WHO guidelines 1999 states lower reference value for normal morphology as $30 \% 1$ and according to that teratospermia was $28 \%$ in our study.

Table II shows the different parameters of normospermic semen including the coefficient of variation. The sperm concentration shows the highest variability followed by motility and morphology respectively.

\section{Table-I}

Normoozospermia and other abnormalities

Categories Number Percentage

\begin{tabular}{lcc}
\hline Normozoospermia & 123 & $61.5 \%$ \\
Azoospermia & 35 & $17.5 \%$ \\
$<10$ sperm/HPF & 15 & $7.5 \%$ \\
Severe oligozospermia & & \\
(<5million/ml) & 6 & $3 \%$ \\
Mild to moderate oligozospermia & & \\
(5-20million/ml) & 5 & $2.5 \%$ \\
Asthenozospermia & 4 & $2 \%$ \\
Teratozospermia & 3 & $1.5 \%$ \\
Oligoteratozospermia & 5 & $2.5 \%$ \\
Oligoasthenoteratozospermia & 4 & $2 \%$ \\
\hline
\end{tabular}

Table-II

Semen of normoozospermic males: different parameters and their variability

\begin{tabular}{|c|c|c|c|}
\hline Semen parameters & Range & Mean \pm std dev & $\begin{array}{l}\text { Coeffi } \\
\text { cient of } \\
\text { variation }\end{array}$ \\
\hline Volume (ml) & $0.5-7$ & $2.75 \pm 1.31$ & 47.63 \\
\hline \multicolumn{4}{|l|}{ Sperm concentration } \\
\hline (million/ml) & $20-200$ & $69.84 \pm 38.26$ & 54.78 \\
\hline Total motility (\%) & $40-90$ & $69.51 \pm 8.86$ & 12.75 \\
\hline \multicolumn{4}{|l|}{ Rapid linear } \\
\hline movement $(\%)$ & $20-70$ & $47.24 \pm 9.72$ & 20.57 \\
\hline \multicolumn{4}{|l|}{ Slow linear } \\
\hline movement $(\%)$ & $5-30$ & $16.26 \pm 3.82$ & 23.49 \\
\hline \multicolumn{4}{|l|}{ Non progressive } \\
\hline motility (\%) & $5-20$ & $6.02 \pm 2.7$ & 38.20 \\
\hline Immotile (\%) & $5-50$ & $29.92 \pm 9.03$ & 30.18 \\
\hline \multicolumn{4}{|l|}{ Normal } \\
\hline morphology (\%) & $15-45$ & $27.56 \pm 7.95$ & 28.85 \\
\hline \multicolumn{4}{|l|}{ Head } \\
\hline abnormality (\%) & $3-40$ & $33.89 \pm 4.65$ & 13.72 \\
\hline \multicolumn{4}{|l|}{ Midpiece } \\
\hline abnormality (\%) & $7-20$ & $16.44 \pm 2.45$ & 14.90 \\
\hline \multicolumn{4}{|l|}{ Tail abnor } \\
\hline mality $(\%)$ & $10-25$ & $21.31 \pm 3.91$ & 18.35 \\
\hline
\end{tabular}

\section{Discussion :}

The objectives of the study is to find out the pattern of semen parameters in our population and to find out the frequency and type of abnormal semen parameters. The findings are azospermia $17.5 \%$ and,$<10$ sperm/HPF $7.5 \%$, severe oligospermia $(<5$ million $/ \mathrm{ml}) 3 \%$, oligospermia $2.5 \%$, oligoasthenoteratospermia $2 \%$. In descriptive analysis of semen parameters of the male 
partners of infertile couples presenting at the University College Hospital in Nigeria ${ }^{4}$, asthenospermia was the most common ( $27.8 \%$ ) abnormalilty, azospermia was $6.7 \%$. Among the multiple factor abnormalities asthenooligospermia was $25.5 \%$, oligoasthenoteratospermia was $13.1 \%$.

The difference may be attributed to the fact that less severe abnormalities of semen are mostly treated with success at primary level. Difficult cases like azoospermia and severe oligospermia are referred to facilities like BSMMU.

A similar study was carried out 3 years back in 2007-2008 in the Infertility unit by Anwary et $\mathrm{al}^{5}$. The sample size was only 50 . There was $4 \%$ normoozospermia, $42 \%$ azospermia and $18 \%$ oligospermia. Frequency of azospermia was again the highest as it is now. The only $4 \%$ frequency of normoozospermia was probably because of inadequate sample size.

The former study by Anwary et $\mathrm{al}^{5}$ had sperm concentration of $19.43+25.18$ million/ml, motility $24.04 \pm 26.45 \%$, normal morphology $21.62 \pm 26.15 \%$. Our study has sperm concentration of $69.84 \pm 38.26$ million/ml, sperm motility $69.51 \pm 8.86 \%$, normal morphology at $27.56 \pm 7.95 \%$. The different means and wider standard deviations in the previous study is probably because the statistical analysis included both abnormal and normal specimens whereas we included only the normal specimens.

The coefficient of variation in our study was highest with sperm concentration (54.78) followed by motility (12.75). It is similar to the findings of a study ${ }^{6}$ where coefficient of variation between subjects was highest for sperm concentration (187.8) followed by sperm motility (98.7).

The male partner can give semen at any time. For optimum results it is advisable to collect semen after a minimum 3 days abstinence. The semen quality depends on time since the last sexual activity. In the absence of ejaculation spermatozoa accumulates in the epididymis , then overflow into the urethra and flushed out in urine ${ }^{7}$.

The fluids of accessory sex organs dilute the concentrated epididymal spermatozoa at ejaculation ${ }^{8}$.Sperm concentration is not a direct measure of testicular sperm output. The total number of sperm per ejaculation (sperm concentration multiplied by semen volume) is a more accurate assessment of capacity of testis to produce spermatozoa and the patency of the male tract . It is recommended to calculate and report the total number of spermatozoa per ejaculate ${ }^{9}$. For this purpose semen volume has to be measured more accurately.

All the azospermic samples and those with $<10$ sperm/HPF had $\mathrm{pH} 8$. Semen $\mathrm{pH}$ increases with time, so high $\mathrm{pH}$ values may provide little clinical useful information ${ }^{10}$.

A major fraction of semen abnormalities in the males attending the Infertility unit of BSMMU is azospermia and severe oligospermia, that are not potentially correctable. These irreversible conditions are amenable to ART (assisted reproductive techniques) using sperm of male partners or not amenable to ART when adoption or donor insemination is an option. More focused attention should be given on the evaluation and counseling of this group of patients. Since most of the patients will not be able to afford ART, we can offer them urological consultation or surgery when feasible, or we can help them with adoption procedures in collaboration with social welfare personals of the hospital.

The semen analysis at Andrology Lab of Infertility unit of BSMMU still follows the WHO1999 guidelines. There has been recent guidelines in the WHO Laboratory Manual for the examination and processing of human semen 5th edition published by WHO in 2010.

According to the recent WHO manual the volume is best measured by collecting the sample in a wide mouth graduated measuring cylinder or by weighing the sample and then calculating the volume ${ }^{13}$. 
The recent WHO manual recommends the use of phase contrast microscopy for semen analysis. It says that counting should be done in a Neuber counting chamber. The semen dilution and the areas of the counting chamber has been changed to allow 200 spermatozoa to be counted per replication ${ }^{16}$.

The Andrology Lab reports motility as rapid linear, slow linear, nonprogressive and immotile. The present edition of WHO laboratory manual for examination and processing of human semen recommends that spermatozoa should be categorized as progressively motile, non progressively motile and immotile ${ }^{17}$.

The reference ranges and the reference limits of WHO manual 2010 are derived from data from between 400-1900 semen samples of recent fathers in eight countries on three continents18. Lower reference limit for semen volume is $1.5 \mathrm{ml}$ ( 5 th centile, $95 \%$ CI 1.4-1.7) ${ }^{19}$. Lower reference limit for sperm concentration is $15 \times 106$ spermatozoa per $\mathrm{ml}$ ( $5^{\text {th }}$ centile $95 \%$ CI $\left.12-16 \times 10^{6}\right)^{15}$.

The lower reference limit for total motility $(\mathrm{PR}+\mathrm{NP})$ is $40 \%$ ( $5^{\text {th }}$ centile $95 \%$ CI $\left.38-42\right)$. The lower reference limit for progressive motility ( $5^{\text {th }}$ centile $95 \% \mathrm{CI}$ ) is $32 \%^{20}$. According to these reference limits the frequencies of oligospermia and asthenospermia would have been lower.

\section{Conclusion :}

The study reveals that severe oligospermia and azospermia are the most common abnormalities among the infertile men presenting at the Infertility unit of BSMMU. Services at this centre should take this into account and should be more oriented towards helping this group of patients. The semen analysis procedure and the reporting system presently practiced at the Andrology Lab of BSMMU should be updated according to the WHO manual 2010. Earlier the changes are made, better will be the quality of service.

\section{References :}

1. Eyvazzadeh AD. Male subfertility. In:Levobic DI, Gordon JD, Taylor RN, editors. Reproductive endocrinology and infertility :
2. Handbook for clinicians- $1^{\text {st }}$ ed. Arlington:Scrub Hill Press Inc. 2005 p208-224

3. Hirsh A. ABC of subfertility Male subfertility. BMJ 2003;327:669-672

4. Kruger TF, Acosta AA et al. New method of evaluating sperm morphology with predictive value for human in vitro fertilization.Urology 1987;30(3):248

5. Adeniji RA, Oleyemi O, Okunlola MA, Aimakhu CO. Patterns of semen analysis of male partners of infertile couples at the University College Hospital, Ibadan. West Afr J Med 2003; 22(3):243245

6. Anwary SA, Alfazzaman M, Islam MR. Male subfertile patients in a tertiary hospital. Mymensingh Med J.2011;20(1):33-39

7. Keel BA. Within and between subject variation in semen parameters in infertile men and normal semen donors. Fertil Seteril 2006; 8591): 128-134

8. De Jonge C. Commentary : forging a partnership between total quality management and the andrology laboratory. Journal of Andrology2004;21;203-205

9. Eliason R. Basic semen analysis. In: Matson P,ed. Current topics in andrology. Perth,Ladybrook Publishing:35-89

10. World Health Organisation. WHO laboratory manual for the examination and processing of human semen $-5^{\text {th }}$ ed.Jeneva: World Health Organisation Press 2010 p33-34

11. World Health Organisation. WHO laboratory manual for the examination and processing of human semen-5th ed.Jeneva: World Health Organisation Press 2010 p17

12. World Health Organisation. WHO laboratory manual for the examination and processing of human semen- $5^{\text {th }}$ ed.Jeneva: World Health Organisation Press 2010 p15

13. World Health Organisation. WHO laboratory manual for the examination and processing of human semen- $5^{\text {th }}$ ed.Jeneva: World Health Organisation Press 2010 p26

14. World Health Organisation. WHO laboratory manual for the examination and processing of human semen $-5^{\mathrm{h}}$ ed.Jeneva: World Health Organisation Press 2010 p3

15. World Health Organisation. WHO laboratory manual for the examination and processing of human semen- $5^{\text {th }}$ ed.Jeneva: World Health Organisation Press 2010 pl6

16. World Health Organisation. WHO laboratory manual for the examination and processing of human semen $-5^{\text {th }}$ ed.Jeneva: World Health Organisation Press 2010 p22

17. World Health Organisation. WHO laboratory manual for the examination and processing of human semen $-5^{\text {th }}$ ed.Jeneva: World 